\title{
Visual and tear function improvement after superficial phototherapeutic keratectomy (PTK) for mid-stromal corneal scarring
}

MURAT DOGRU. CHIKAKO KATAKAMI, MASATO MIYASHITA, ETSUKO HIDA, MAMORU UENISHI, KAZUAKI TETSUMOTO, SANAE KANNO, TERUO NISHIDA, AKIO YAMANAKA

\begin{abstract}
Purpose To study the changes in visual and tear film function following superficial excimer laser phototherapeutic keratectomy in patients with mid-stromal corneal scars. Methods Fourteen eyes of 14 patients with mid-stromal corneal scars seen at the Department of Ophthalmology at Kobe Kaisei Hospital underwent superficial phototherapeutic keratectomy (PTK). The subjects underwent routine ophthalmic examinations, corneal sensitivity measurements, tear film break-up time (BUT), Schirmer test and tear film lipid layer interferometry. Thirty eyes of 15 normal control subjects were also studied. The patients and the control subjects were compared for pre-PTK tear function parameters and tear film lipid layer interferometry grade. The alterations in these parameters within 6 months following PTK were also determined.
\end{abstract}

Results Visual improvement was achieved in 12 eyes (86\%). A hyperopic shift was observed in all eyes. The average pre-PTK corneal sensitivity and tear film BUT were lower in patients compared with control subjects before PTK. Tear film lipid layer interferometry grades were also higher in the patients than the controls before PTK. All these parameters improved gradually and significantly after PTK. Schirmer test results did not show any significant alterations after PTK.

Conclusion We conclude that PTK is an effective means of treating corneal scars and attaining visual improvement, even in cases with deeper corneal involvement, and may obviate the need for corneal transplantation. Simultaneous improvements in corneal sensitivity and tear film stability suggest favourable effects of PTK on the ocular surface.
Key words Corneal sensitivity, Interferometry, Phototherapeutic keratectomy, Tear film, Tear film lipid layer

Excimer lasers have enabled ophthalmologists to treat superficial corneal pathologies more efficiently. The available excimer laser systems remove corneal tissue not only with extreme precision but with minimal adjacent tissue damage.

Increased interest in excimer laser phototherapeutic keratectomy (PTK) in the mid1980s stimulated several experimental and clinical studies reporting successful removal of superficial opacities from the corneal visual axis and attainment of smooth regular surfaces. Such studies also report visually satisfactory results following PTK of a wide variety of superficial corneal opacities. Although PTK has been proven to be successful in the management of superficial corneal opacities, keratoplasty procedures are widely accepted as appropriate for deeper corneal involvement.

We aimed to study whether PTK would be beneficial in patients with mid-stromal corneal scars in whom a keratoplasty procedure could not be performed. Therefore, we performed visual acuity, refraction, corneal sensitivity, tear film break-up time, tear film lipid layer interferometry and Schirmer test measurements; comparing the results with those of normal control subjects and also looking at the early alterations in these parameters within 6 months after PTK.

\section{Materials and methods}

\section{Subjects and examinations}

Fourteen eyes of 14 patients with deep corneal scars ( 9 men, 5 women) between 34 and 86 years of age (mean $68.6 \pm 11.9$ years) underwent excimer laser PTK at Kobe Kaisei Hospital Eye Clinic between September 1998 and September
M. Dogru

M. Miyashita

H. Hida

M. Uenishi

A. Yamanaka

Department of Ophthalmology

Kobe Kaisei Hospital

Kobe, Japan

C. Katakami

Department of

Ophthalmology

Kobe University School of

Medicine

Kobe, Japan

\section{K. Tetsumoto}

Department of Ophthalmology

Shakai Hoken Kobe Chuo

Hospital

Kobe, Japan

S. Kanno

Department of

Ophthalmology

Hyogo College of Medicine

Hyogo, Japan

\section{T. Nishida}

Department of Ophthalmology

Yamaguchi University

School of Medicine

Ube, Japan

Chikako Katakami, MD, PhD Department of Ophthalmology Kobe University School of Medicine

7-5-2 Kusunokicho, Chuoku Kobe 650-0017, Japan

Tel: +81783826048

Fax: +8178 3826059

\section{Proprietary interest: None}

This work was presented at the 22nd Mid-Japan

Congress of

Ophthalmology, 21 November 1999, Kyoto, Japan

Received: 20 December 1999 Accepted in revised form: 13 April 2000 
Table 1. Clinical features of the patients

\begin{tabular}{|c|c|c|c|c|c|c|c|c|c|}
\hline \multirow{2}{*}{\multicolumn{2}{|c|}{$\begin{array}{c}\text { Patient Sex/Age } \\
\text { no. (years) }\end{array}$}} & \multirow[b]{2}{*}{ Aetiology } & \multirow{2}{*}{$\begin{array}{c}\text { Follow-up } \\
\text { (months) }\end{array}$} & \multirow{2}{*}{$\begin{array}{l}\text { Central } \\
\text { corneal } \\
\text { ickness }(\mu \mathrm{m})\end{array}$} & \multirow{2}{*}{$\begin{array}{c}\text { Ablation } \\
\text { depth } \\
(\mu \mathrm{m})\end{array}$} & \multicolumn{2}{|c|}{ Refractive error (D) } & \multicolumn{2}{|c|}{$\begin{array}{c}\text { Best corrected } \\
\text { visual acuity }\end{array}$} \\
\hline & & & & & & Initial & Final & Initial & Final \\
\hline 1 & $\mathrm{M} / 65$ & Herpetic & 15 & $422 \pm 7$ & 90 & $-1.75 c-1.0 \times 60^{\circ}$ & $+1.00 c-1.5 \times 75^{\circ}$ & $20 / 25$ & $20 / 16$ \\
\hline 2 & $\mathrm{M} / 34$ & Unknown & 12 & $402 \pm 4$ & 70 & $+0.50 c-0.75 \times 80^{\circ}$ & $+1.50 c-0.50 \times 85^{\circ}$ & $20 / 100$ & $20 / 32$ \\
\hline 3 & $\mathrm{M} / 73$ & Post-infectious & 12 & $504 \pm 2$ & 100 & $-1.75 c-1.25 \times 90^{\circ}$ & $+2.00 \mathrm{c}-1.5 \times 105^{\circ}$ & $20 / 200$ & $20 / 63$ \\
\hline 4 & $\mathrm{~F} / 63$ & Traumatic & 9 & $593 \pm 4$ & 120 & -3.00 & +3.00 & $20 / 200$ & $20 / 100$ \\
\hline 5 & $\mathrm{~F} / 71$ & Traumatic & 13 & $511 \pm 2$ & 120 & Not measurable & \pm 5.00 & HM & $20 / 200$ \\
\hline 6 & $\mathrm{~F} / 74$ & Traumatic & 9 & $496 \pm 4$ & 100 & Not measurable & +2.00 & HM & $20 / 200$ \\
\hline 7 & $\mathrm{M} / 62$ & Herpetic & 7 & $517 \pm 8$ & 100 & Not measurable & +4.00 & $\mathrm{HM}$ & $20 / 100$ \\
\hline 8 & $M / 69$ & Unknown & 14 & $638 \pm 12$ & 120 & -1.50 & +4.50 & $20 / 200$ & $20 / 63$ \\
\hline 9 & $\mathrm{M} / 86$ & Unknown & 7 & $498 \pm 4$ & 90 & $+2.00 \mathrm{c}+0.50 \times 175^{\circ}$ & $+5.00 c+0.75 \times 5^{\circ}$ & $20 / 63$ & $20 / 50$ \\
\hline 10 & $\mathrm{M} / 59$ & Post-infectious & 6 & $494 \pm 6$ & 90 & Not measurable & +2.50 & HM & $20 / 200$ \\
\hline 11 & $\mathrm{M} / 61$ & Herpetic & 6 & $486 \pm 2$ & 120 & -1.00 & +3.00 & $20 / 200$ & $20 / 200$ \\
\hline 12 & $\mathrm{~F} / 64$ & Traumatic & 6 & $501 \pm 3$ & 90 & -6.00 & -3.00 & $20 / 200$ & $20 / 20$ \\
\hline 13 & $\mathrm{~F} / 66$ & Herpetic & 11 & $520 \pm 8$ & 120 & -1.00 & +5.50 & $20 / 200$ & $20 / 200$ \\
\hline 14 & $\mathrm{M} / 66$ & Traumatic & 8 & $558 \pm 14$ & 120 & Not measurable & +3.75 & HM & $20 / 200$ \\
\hline
\end{tabular}

1999. The aetiologies of the corneal opacities are shown in Table 1. All patients underwent routine ophthalmic examinations including best corrected Landolt visual acuity, slit-lamp microscopy, anterior segment photography, Eye Sys corneal topography, pachymetry, fundoscopy, Cochet-Bonnet corneal sensitivity measurement, tear film break-up time, tear film lipid layer interferometry and a Schirmer test, which were performed before PTK as well as 1 week, 1 month, 3 months and 6 months after PTK. A careful examination of the lid margins was also conducted. All examinations and gradings were performed by the same researcher. Thirty eyes of 15 age- and sex-matched healthy individuals were taken as controls. Informed consent for the procedures was obtained. All patients were also questioned about the presence of symptoms of eye fatigue, dryness and irritation before and 6 months after PTK. None of the patients had a history of StevensJohnson syndrome, of chemical, thermal or radiation injury, or of any ocular disease except the corneal opacity. Patients and control subjects also did not have any history of systemic diseases, or of drug or contact lens use, and had not undergone any ocular surgery that would create an ocular surface problem.

Measurement of corneal sensitivity was performed by using a Cochet-Bonnet aesthesiometer. The measurements were begun with the nylon filament $(\Phi 0.12 \mathrm{~mm})$ fully extended. The tip of the filament was supplied perpendicularly to the surface of the central cornea making certain not to touch the eye lashes, and was pushed until the fibre's first visibly bent. The length of the fibre was gradually decreased until a blink reflex was observed. The length was recorded in units of millimetres. A corneal sensitivity measurement of less than $40 \mathrm{~mm}$ was regarded as low.

The standard tear film break-up time (BUT) measurement was performed. Moistened fluorescein strips were introduced into the conjunctival sac with minimal stimulation and were undetected by the patients. The subjects were then instructed to blink several times for a few seconds to ensure adequate mixing of fluorescein. The interval between the last complete blink and the appearance of the first corneal black spot in the stained tear film was measured three times and the mean value of the measurements was calculated. A BUT value of less than $10 \mathrm{~s}$ was considered abnormal.

The tear film status and the lipid layer were also evaluated by a DR-1 interferometer system (Kowa, Japan). The principles of the system using interference patterns has been described elsewhere. ${ }^{1}$ The tear lipid layer interference patterns have been classified by Yokoi et al. into five grades: grade 1, somewhat grey colour, uniform distribution; grade 2, grey colour, non-uniform distribution; grade 3, few colours, non-uniform distribution; grade 4, many colours, non-uniform distribution; grade 5, corneal surface partially exposed. Grade 3 and above were regarded as indicators of a dry eye state as reported previously. ${ }^{1}$ The patients were instructed not to instil their medications for at least $6 \mathrm{~h}$ before tear film lipid layer interferometry measurements. The measurements were carried out at the same time interval following the last complete blink in all patients.

For further evaluation of tears, the standard Schirmer test with topical anaesthesia $(0.4 \%$ oxybuprocaine chloride) was performed. The standardised strips of filter paper (Alcon, Texas) were placed in the lateral canthus away from the cornea and left in place for $5 \mathrm{~min}$ with the eyes closed. Readings were reported in millimetres of wetting for $5 \mathrm{~min}$. A reading of less than $5 \mathrm{~mm}$ was referred to as dry eye.

\section{The PTK procedure}

Due to a long waiting list for penetrating keratoplasty in Japan, only those patients with mid-stromal corneal scars who consented to a trial of excimer laser corneal ablation initially, until fresh donor cornea became available, underwent the PTK procedure. The transepithelial corneal ablations were carried out using the Nidek-EC 5000 excimer laser under topical $0.4 \%$ oxybuprocaine anaesthesia. We used a 5-6.0 $\mathrm{mm}$ ablation zone, $70-120 \mu \mathrm{m}$ ablation depth and a pulse frequency of $30 \mathrm{~Hz}$. 
A transition zone (TZ) of $1 \mathrm{~mm}$ was set in all eyes. Sodium hyaluronate $0.1 \%$ was applied as necessary during the procedures to achieve a smoother ablation. The patients were fitted with soft therapeutic contact lenses at the end of the procedure and were prescribed topical ofloxacin and sodium hyaluronate eye drops until corneal epithelisation. The patients were then put on fluorometholone $0.1 \%$ and ofloxacin eye drops for 6 months, after which they were gradually tapered. Those patients who developed subepithelial corneal haze were evaluated by the Fantes grading system and were prescribed betamethasone $0.1 \%$ eye drops. Patients with a history of herpetic keratitis received oral acyclovir $1000 \mathrm{mg} /$ day before and for 3 weeks after PTK to prevent any recurrence.

\section{Statistical analysis}

Data were processed using StatView software (1988, Abacus Concepts, San Diego, CA). The Mann-Whitney test was used for the analyses of non-parametric values. A probability level less than $1 \%$ was considered statistically significant. The analysis of categorical data was performed by Fisher's exact probability test, with the probability level set at $1 \%$ for statistical significance.

\section{Results}

\section{Clinical features}

None of the eyes had pre-operative corneal epithelial erosions in this study. All patients complained of symptoms of eye fatigue, dryness and irritation which disappeared after PTK. All eyes had complete and uneventful corneal re-epithelisation within 3 days following PTK. Four patients developed Fantes Grade II subepithelial haze 3-4 months after PTK which disappeared within 6 months. No visually disabling complications related to PTK were observed. Recurrence of active herpetic disease was not encountered in this study.

\section{Visual outcome}

Best corrected visual acuity improved in 12 eyes despite the presence of some degree of corneal stromal opacity after PTK. A representative case is shown in Fig. 1. Six eyes $(43 \%)$ had an improvement of more than 2 lines and 2 eyes (14\%) had an improvement of 1 line of Landolt corrected visual acuity. Two eyes showed no change in visual acuity following PTK. One of these 2 eyes had myopic macular chorioretinal atrophy and the other had cellophane maculopathy. Visual acuity increased from hand movements to $20 / 100$ or $20 / 200$ in 4 eyes (29\%). Worsening of visual acuity was not encountered in any patient (Table 1).

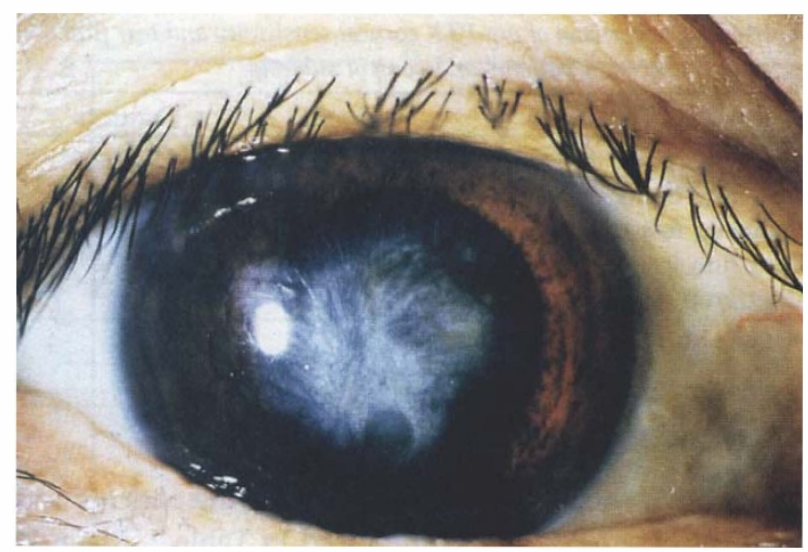

(a)

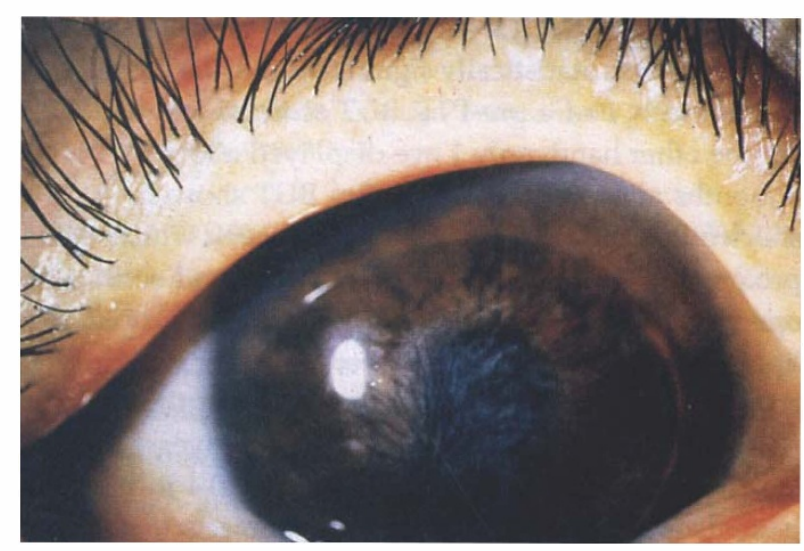

(b)

Fig. 1. Herpetic corneal scar: (a) before PTK, (b) 8 months after PTK.

\section{Refractive outcome}

All patients had a hyperopic shift ranging between +1.0 and $+6.5 \mathrm{D}$ (mean $3.98 \pm 1.81 \mathrm{D}$ ) following PTK. Five patients in whom post-operative anisometropia became a problem were successfully managed with gas-permeable hard contact lens wear. Post-PTK Eye Sys corneal topography and pachymetry did not reveal corneal ectasia in any of the patients. Corneal topography showed gradual central corneal flattening for 3 months which stabilised afterwards.

\section{Corneal sensitivity}

The average pre-PTK corneal sensitivity was $39.1 \pm 5.5 \mathrm{~mm}$ in the patients compared with $58.3 \pm 0.6 \mathrm{~mm}$ in the control subjects, as shown in Table 2 $(p<0.001)$. Thirteen eyes $(93 \%)$ had a Cochet-Bonnet corneal sensitivity recording of less than $40 \mathrm{~mm}$ preoperatively. There were no eyes with a low corneal sensitivity reading 6 months after PTK. Corneal sensitivity showed a statistically significant increase at the first, third and sixth post-PTK months, as shown in Fig. $2(p<0.001)$. The patients with herpetic leucoma tended to have a slower recovery and the corneal sensitivity measurements were slightly lower at the 6 month follow-up examination compared with other patients (Table 3). 
Table 2. Comparison of pre-PTK corneal sensitivity and tear function parameters between patients and control subjects

\begin{tabular}{lrc}
\hline & \multicolumn{1}{c}{ Patients } & \multicolumn{1}{c}{ Controls } \\
\hline Corneal sensitivity (mm) & $39.1 \pm 5.5$ & $58.3 \pm 0.6^{*}$ \\
Tear film break-up time (s) & $6.5 \pm 2.4$ & $14.0 \pm 1.2^{*}$ \\
Schirmer test (mm) & $6.5 \pm 1.7$ & $11.5 \pm 0.6$ \\
Tear film lipid layer & $3.5 \pm 0.4$ & $1.2 \pm 0.4^{*}$ \\
interferometry grade & & \\
\hline
\end{tabular}

${ }^{*} p<0.001 ;$ Mann-Whitney test.

\section{Tear function parameters}

The pre-PTK tear function parameters of the patients and the control subjects are summarised in Table 2. Mean pre-PTK values of the BUT test were $6.5 \pm 2.4 \mathrm{~s}$ in the patients and $14.0 \pm 1.2 \mathrm{~s}$ in the control group. The difference was statistically significant $(p<0.001)$. All eyes in this study had a pre-PTK BUT score of less than $10 \mathrm{~s}$. On the other hand, only 1 eye displayed a low BUT score 6 months after PTK. The tear film BUT showed shortening at the first post-operative week which then prolonged significantly at the first, third and sixth postoperative months as shown in Fig. $3(p<0.001)$. Tear film lipid layer interferometry showed smoothing of the corneal surface with a regular tear film distribution after PTK (Fig. 4). The average tear film lipid layer interference grade before PTK was $3.5 \pm 0.4$ in the patients and $1.2 \pm 0.4$ in the control subjects $(p<0.001)$. No eye showed a pre-PTK grade 1 or 2 (normal) tear film interferometry pattern whereas all eyes revealed normal grading at the sixth post-operative month. The tear film interferometry grading showed a statistically significant gradual improvement 1 month, 3 months and 6 months after PTK as shown in Fig. $5(p<0.001)$.

Pre-PTK Schirmer test value averaged $6.5 \pm 1.7 \mathrm{~mm}$ in the patients versus $11.5 \pm 0.6 \mathrm{~mm}$ in the controls $(p>0.001)$. The pre-PTK and first week, first month, third month and sixth month post-PTK Schirmer test values were $6.5 \pm 1.7 \mathrm{~mm}, 6.3 \pm 1.9 \mathrm{~mm}, 6.1 \pm 0.7 \mathrm{~mm}$, $6.6 \pm 1.1 \mathrm{~mm}$ and $6.4 \pm 1.3 \mathrm{~mm}$ respectively. Postoperative Schirmer test results did not show any significant differences.

\section{Discussion}

Many studies on PTK have reported beneficial results in a wide variety of pre-operative diagnoses. Amongst these, corneal scars represent one group where it is not always easy to place an indication for PTK. ${ }^{2-5}$ While PTK can be visually rewarding for superficial corneal opacities, visual outcome can be variable and sometimes

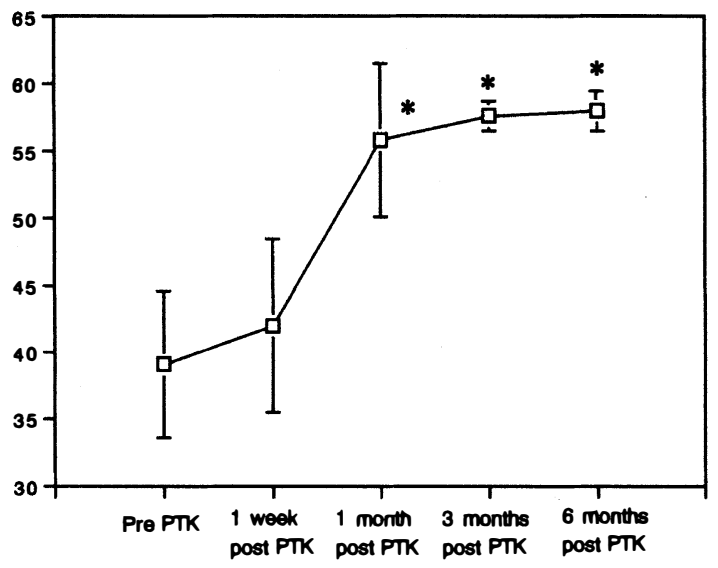

Fig. 2. Change in corneal sensitivity after PTK. * $\mathrm{p}<0.001$, Fisher's exact test.

disappointing for deeper corneal involvement, which is traditionally approached with penetrating or lamellar keratoplasty. ${ }^{6-9}$ We have previously reported that excimer laser PTK has favourable effects on the health of the ocular surface in a variety of corneal opacities including Avellino, lattice and granular corneal dystrophy, band keratopathy and superficial corneal scars. ${ }^{10}$ We aimed to study the visual and tear film changes in 14 patients with mid-stromal corneal scarring in whom a keratoplasty procedure could not be performed within a short period of time due to a long waiting list for penetrating keratoplasty in Japan and who consented to an initial trial of a PTK procedure until fresh donor cornea became available.

We attained visual improvement in 12 eyes (86\%) and saw that PTK could obviate the need for keratoplasty. Two patients who had no change in their visual acuity after PTK still reported a clearer vision compared with their pre-PTK status. All eyes ended up with a hyperopic refraction after PTK in this series. Five patients developed anisometropia due to induced hyperopia and were successfully managed with gas-permeable hard contact lens wear. A hyperopic shift is commonly observed after PTK and remains a major problem. The difference in the energy distribution due to shielding by the debris of the photoablation, difference of the ablation rates between central and peripheral cornea, corneal epithelial and stromal healing responses have all been implicated as possible explanations for the hyperopic shift. ${ }^{11-13}$ Controlled long-term studies on the effect of factors such as ablation depth, ablation zone diameter, transition zone setting, masking agent use, epithelial

Table 3. Aetiology-specific comparison of corneal sensitivity ( $\mathrm{mm}$ ) before and after PTK

\begin{tabular}{|c|c|c|c|c|c|}
\hline \multirow[b]{2}{*}{ Aetiology of corneal scar } & \multirow[b]{2}{*}{ Before PTK } & \multicolumn{4}{|c|}{ After PTK } \\
\hline & & 1 week & 1 month & 3 months & 6 months \\
\hline Traumatic ( $n=5$ eyes) & $44.0 \pm 2.6$ & $50.0 \pm 2.4$ & $57.8 \pm 2.7$ & $58.5 \pm 2.1$ & $58.4 \pm 2.3$ \\
\hline Herpetic ( $n=4$ eyes) & $31.5 \pm 2.5$ & $31.0 \pm 2.8$ & $45.6 \pm 1.4$ & $47.8 \pm 1.2$ & $48.0 \pm 2.4$ \\
\hline Post-infectious ( $n=2$ eyes) & $37.5 \pm 3.5$ & $42.5 \pm 3.5$ & $56.2 \pm 1.7$ & $57.5 \pm 3.5$ & $58.5 \pm 2.1$ \\
\hline Unknown ( $n=3$ eyes) & $40.0 \pm 1.8$ & $45.0 \pm 1.6$ & $57.6 \pm 1.1$ & $58.3 \pm 2.8$ & $59.0 \pm 1.7$ \\
\hline
\end{tabular}




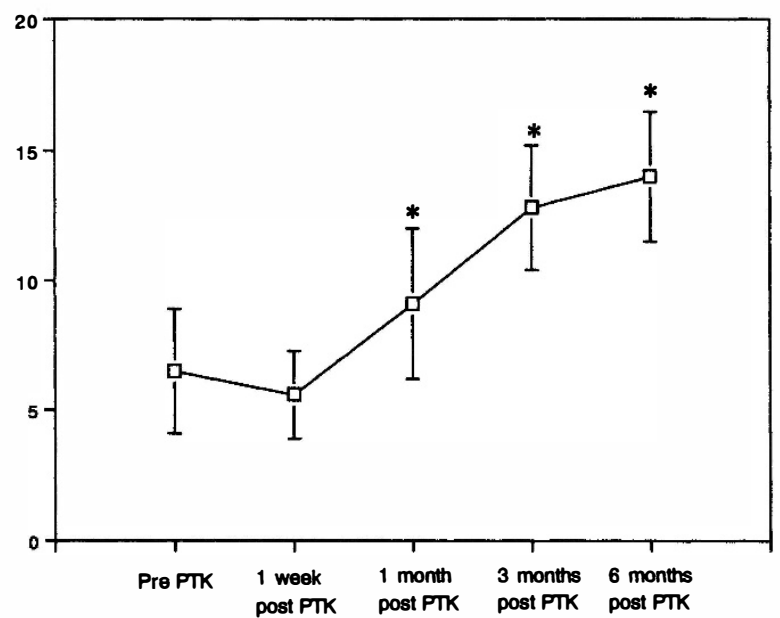

Fig. 3. Change in tear film break-up time after PTK. ${ }^{*} \mathrm{p}<0.001$, Fisher's exact test.

hyperplasia and subepithelial haze on induced hyperopia would provide very interesting information. We also noted that symptoms of eye fatigue and irritation dramatically improved after PTK in all patients. We attributed such symptomatology to the presence of a BUT-deficient dry eye state. ${ }^{14,15}$ as described by Lemp and Barsam et al. and the irregularity of the corneal surface before PTK. Indeed, the tear film was significantly unstable in the patients compared with the control subjects and tear stability improved remarkably within 6 months after PTK. This, we believe, was mainly due to attainment of a regular corneal surface and a better epithelium-tear film interaction following PTK. Another explanation may be the change in quantity and/or quality of mucin secretion by a healthier corneal epithelium after re-epithelisation. Tear film mucin quantification before and after PTK would be very interesting. One other piece of evidence for improvement of the tear film after PTK came from tear film lipid layer interferometry measurements. Our patients had higher grades of interferometry examinations before PTK,

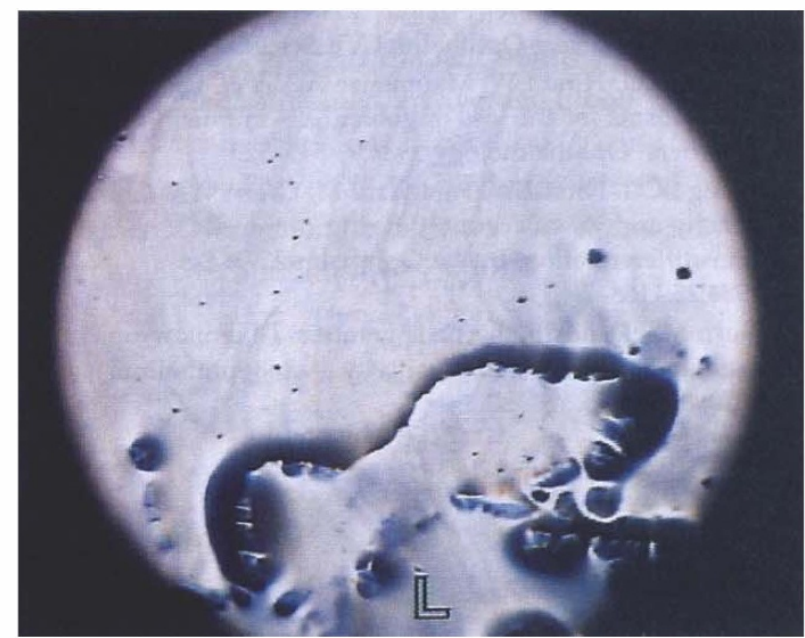

(a)
Grade

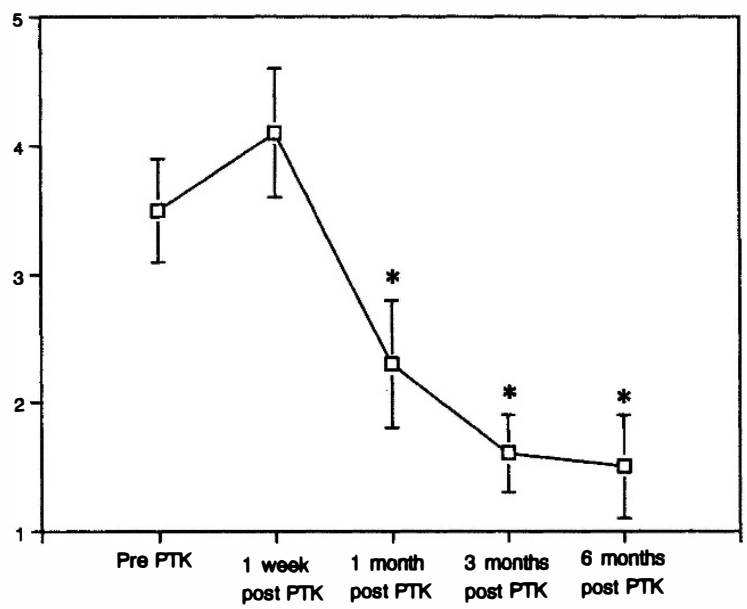

Fig. 5. Change in tear film lipid layer interferometry grade after PTK. ${ }^{*} \mathrm{p}<0.001$, Fisher's exact test.

similar to dry eye states. ${ }^{16}$ Through careful clinical and ophthalmological examination, we ruled out the possibility of systemic lipid disorders, Meibomian gland dysfunction or aqueous tear deficiency as the cause of higher grades of interference patterns. It has been reported that mucin-lipid interaction is required for the Meibomian lipids to spread uniformly over the outermost surface of the tear film. Mucin might coacervate at the surface of the corneal epithelium and be gradually diluted towards the surface of the tear film. Thus the three layers of the tear film might not be clearly distinguishable. ${ }^{17}$ This might explain the gradual improvement in BUT scores and interference pattern grades, which we attribute to a better mucin-lipid layer interaction after achievement of a regular corneal epithelial surface and probably mucin secretion by a functionally healthier corneal epithelium. However, further studies on the alterations of the lipid layer and its components in dry eyes should be carried out.

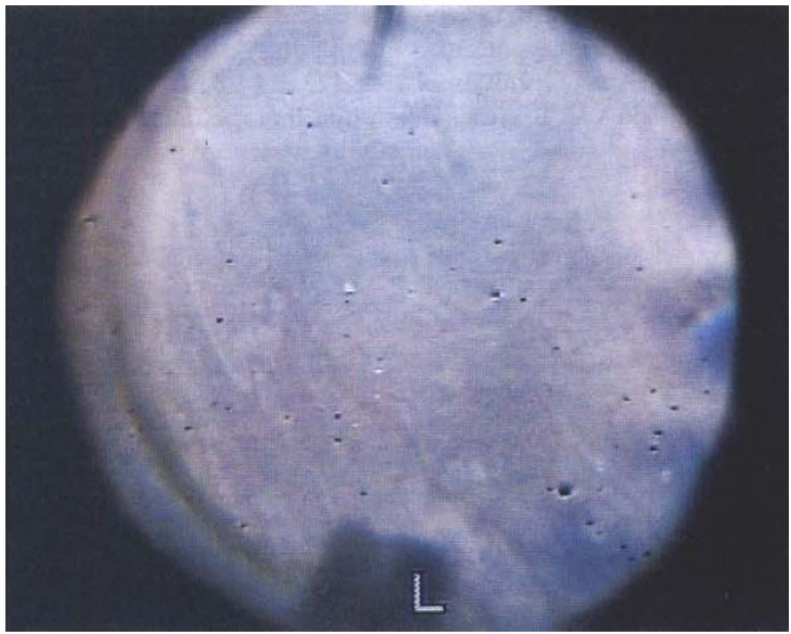

(b)

Fig. 4. Tear film surface observed by tear film interferometry in a patient with traumatic corneal leucoma. (a).Irregularity of the corneal surface and tear film distribution before PTK. (b) Regular corneal surface and tear film distribution attained 3 months after PTK. 
Finally, another interesting finding was that the corneal sensitivity gradually improved after PTK Corneal nerves have been shown to start regenerating within $24 \mathrm{~h}$ after PTK. A significantly lower pre-PTK corneal sensitivity in the patients strongly implied epithelial and stromal disease. Given that the ablation depth varied between 70 and $120 \mu \mathrm{m}$ in this group of patients, we presume that we were able to remove the epithelial and subepithelial corneal nerve plexus. Improvement in corneal sensitivity within 6 months after PTK suggested that uneventful corneal regeneration took place in our patients, similar to the findings in other reports. ${ }^{18-20}$

Corneal nerves are said to maintain the health of the ocular surface through their trophic action. ${ }^{21,22}$ We believe that an increased corneal sensitivity should have favourable effects on the milieu of corneal epithelial cells and corneal stroma. One other interesting finding was that the improvement in corneal sensitivity was comparatively slower in patients with herpetic corneal scar. Indeed, decreased corneal sensitivity has been reported in patients with herpetic keratitis and the extent of recovery of corneal sensitivity has been related to the severity of corneal involvement. ${ }^{23}$ Whether a delayed healing response is specific or not for herpetic leucomas after PTK waits to be answered by longer and larger controlled studies.

Concurrent improvements in corneal sensitivity, visual and tear film function were attained in this set of patients with mid-stromal corneal scarring. We conclude that PTK is a relatively safe and effective means of treating corneal scars and that visual improvement can be attained even in cases with mid-stromal corneal involvement despite the presence of some degree of remaining corneal opacity. In this sense, PTK may also offer an alternative to corneal transplantation. We therefore believe in the necessity of further and broader case-controlled clinicopathological studies in this field.

\section{References}

1. Yokoi N, Takehisa Y, Kinoshita S. Correlation of tear lipid layer interference patterns with the diagnosis and severity of dry eye. Am J Ophthalmol 1996;122:814-28.

2. Thompson VM. Excimer laser phototherapeutic keratectomy: clinical and surgical aspects. Ophthalmic Surg Lasers 1995;26:461-72.

3. Hersh PS, Spinak A, Garrana R, Mayers M. Phototherapeutic keratectomy: strategies and results in 12 eyes. Refract Corneal Surg 1993;9:S90-5.

4. Thompson V, Durrie DG, Cavanaugh TB. Philosophy and technique for excimer laser phototherapeutic keratectomy. Refract Corneal Surg 1993;9:S81-5.
5. Sher NA, Bowers RA, Zabel RW. Clinical use of the 193-nm excimer laser in the treatment of corneal scars. Arch Ophthalmol 1991;109:491-8.

6. Migden M, Elkins B, Clinch TE. Phototherapeutic keratectomy for corneal scars. Ophthalmic Surg Lasers 1996;27:D503-7.

7. Fagerholm P, Ohman L, Orndahl M. Phototherapeutic keratectomy in herpes simplex keratitis. Acta Ophthalmol 1994;72:457-60.

8. Campos M, Nielsen S, Szerenyi K, Garbus JJ, McDonnell PJ. Clinical follow up of phototherapeutic keratectomy for treatment of corneal opacities. Am J Ophthalmol 1993;115:433-40.

9. Fagerholm P, Fitzsimmons TD, Omdahl M, Ohman L, Tengroth B. Phototherapeutic keratectomy: long term results in 166 eyes. J Refract Corneal Surg 1993;9:S76-81.

10. Dogru M, Katakami C, Miyashita M, Hida E, Uenishi M, Tetsumoto $\mathrm{K}$, et al. Ocular surface changes after excimer laser phototherapeutic keratectomy. Ophthalmology 2000;107:1144-52.

11. Fantes FE, Hanna KD, Waring GO III. Wound healing after excimer laser keratomileusis (photorefractive keratectomy) in monkeys. Arch Ophthalmol 1990;108:665-75.

12. Liu C. Hyperopic shift and the use of masking agents in excimer laser superficial keratectomy [letter]. Br J Ophthalmol 1992;76:62-3.

13. Amm M, Duncker GIW. Refractive changes after phototherapeutic keratectomy. J Cataract Refract Surg 1997;23:839-44.

14. Lemp MA. Dry eye syndromes: treatment and clinical trials. In: Lacrimal gland, tear film and dry eye syndrome. New York: Plenum Press, 1994.

15. Barsam PL, Sampson WG, Feldman GL. Treatment of the dry eye and related problems. Ann Ophthalmol 1972;4:122-9.

16. Danjo Y, Hamano T. Observation of precorneal tear film in patients with Sjögren's syndrome. Acta Ophthalmol Scand 1995;73:501-5.

17. Holly FJ. Formation and rupture of the tear film. Exp Eye Res 1973;15:515-25.

18. Linna T, Tervo T. Real-time confocal microscopic observations on human corneal nerves and wound healing after excimer laser photorefractive keratectomy. Curr Eye Res 1997;16:640-9.

19. Ishikawa T, Kanai A, Aquavella JV, et al. Correlation between corneal sensitivity and nerve regeneration following excimer laser ablation. J Jpn Ophthalmol Soc 1995;2:135-42.

20. Trabucci G, Brancato R, Verdi M, et al. Corneal nerve damage and regeneration after excimer laser photokeratectomy in rabbit eyes. Invest Ophthalmol Vis Sci 1994;35:229-35.

21. Tseng SCG, Hirst LW, Maumenee AE, et al. Possible mechanisms for the loss of goblet cells in mucin-deficient disorders. Ophthalmology 1984;91:545-52.

22. Tseng SCG, Hirst LW, Farazdagi M, Green WR. Goblet cell density and vascularisation during conjunctival transdifferentiation. Invest Ophthalmol Vis Sci 1984;25:1168-76.

23. Norn MS. Dendritic herpetic keratitis. IV. Follow-up examination of corneal sensitivity. Acta Ophthalmol 1970;48:383-95. 